\title{
DAMPAK DAN TANTANGAN DALAM IMPLEMENTASI SOCIAL MEDIA MARKETING UNTUK UMKM
}

\author{
Yustina Chrismardani, Triana Setiyarini
}

Dosen Jurusan Manajemen Fakultas Ekonomi dan Bisnis

Universitas Trunojoyo Madura

\begin{abstract}
ABSTRAK
Social media marketing merupakan variasi alat pemasaran yang dapat digunakan secara mudah dan tidak berbiaya, bila dibandingkan dengan alat pemasaran lainnya. Dengan biaya yang lebih rendah daripada alat pemasaran yang lain, UMKM cenderung cocok menggunakan metode social media marketing untuk memperkenalkan produknya, membangun hubungan dengan pelanggan dan memperkuat merk nya. Pada kenyatannya, hanya 30\% usaha di Indonesia yang menggunakan instrument digital, sehingga dibutuhkan lebih banyak riset untuk mengeksplorasi perspektif dari perusahaan, terutama dalam memahami penghalang atau penghambat dalam penggunaan social media marketing. Tujuan dari riset ini adalah mendeskripsikan konsep social media marketing, penggunaan social media sebagai sarana promosi untuk UMKM, dampak dan tantangan dihadapi oleh UMKM dalam penggunaan social media. Merencanakan untuk menggunakan social media sebagai alat pemasaran yang kompetitif, memerlukan isi pesan yang dapat menarik perhatian pelanggan. Selain itu, juga dibutuhkan ketulusan, perhatian dan respon dengan cepat dalam berkomunikasi dengan pelanggan target. Tantangan dalam penggunaan social media marketing oleh UMKM yang meliputi factor internal dan eksternal, merupakan hal yang harus dihadapi dan diantisipasi agar mencapai keberhasilan dalam social media marketing.
\end{abstract}

\section{Pendahuluan}

Setiap bisnis modern berharap untuk menggapai sukses di dalam pasarnya. Komunikasi pemasaran dibutuhkan untuk menjalin komunikasi dengan pelanggan dan calon pelanggan secara efektif. Komunikasi merupakan alat untuk membentuk opini public yang untuk masa sekarang ini diperlukan untuk menjamin adanya koneksi antara pembeli dan penjual. Keller (2012) menyatakan bahwa komunikasi pemasaran terdiri dari 8 alat, yaitu advertising, sales promotion, event dan pengalaman, public relation dan publisitas, direct marketing, interactive marketing, word of mouth marketing, personal selling. Sering perkembangan teknologi, social media menawarkan metode komunikasi pemasaran yang unik (Eagleman, 2013). Social media marketing menggunakan aplikasi social media untuk memenuhi pemasaran tradisional. Aktivitas pemasaran via aplikasi online membangun informasi dan kolaborasi diantara usernya 
(Kaplan and Haenlein, 2010). Contoh social media yang berkembang saat ini adalah twitter, facebook, myspace, youtube, Instagram, path, whatsapp, line, dll.

Berdasarkan data per Januari 2019, dari 260 juta penduduk Indonesia, sebanyak 150 juta atau sebesar 56\%, merupakan pengguna social media (www.wearesocial.com). Tiga social media yang banyak digunakan oleh penduduk Indonesia adalah Youtube, Whatsapp dan Instagram. Data social media yang digunakan oleh penduduk Indonesia disajikan dalam gambar berikut ini.

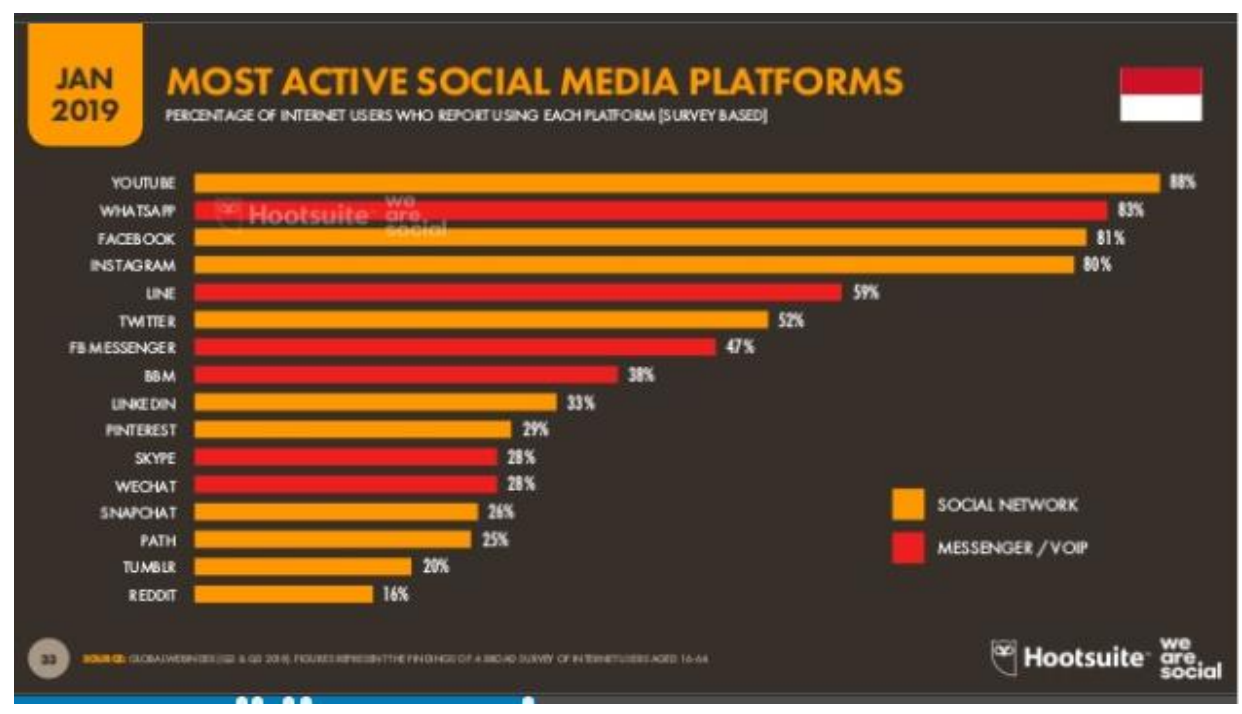

Gambar 1 Platform social media yang digunakan di Indonesia (www.wearesocial.com)

Melalui social media yang diakses oleh 56\% penduduk Indonesia, terjadi exposure atau paparan advertising berbagai produk dan jasa. Besarnya audiens dari advertising di social media mencapai 130 juta untuk Facebook; 62 juta untuk Instagram; 6,43 juta untuk Twitter; 3,8 juta untuk Snapchat dan 12 juta untuk LinkedIn (www.wearesocial.com). Dengan melihat besarnya pengguna social media dan prosentase interaksi user di social media, maka Indonesia merupakan pasar yang besar untuk implementasi social media marketing. 


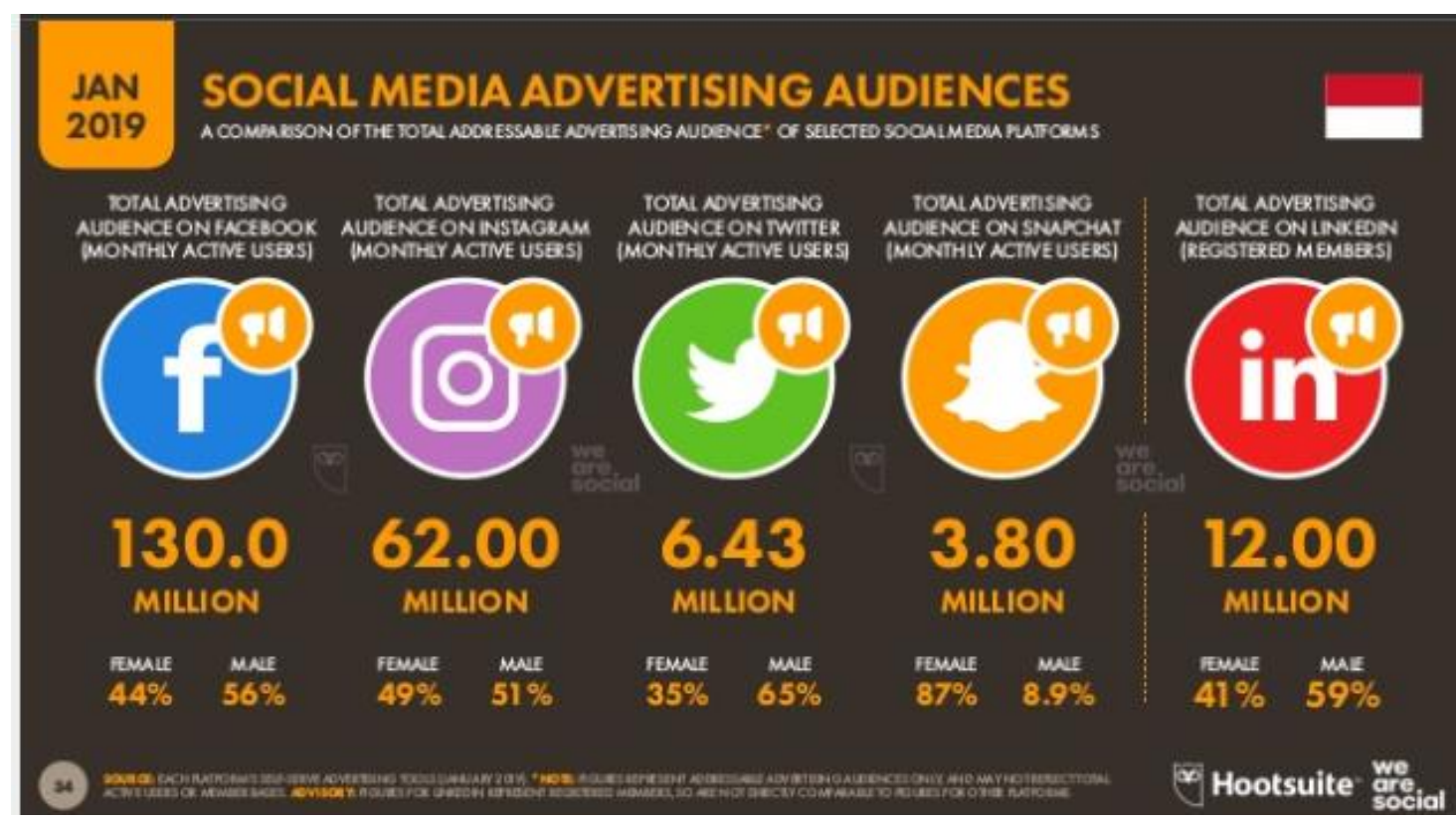

Gambar 2 Audiens advertising di masing-masing platform social media

(www.wearesocial.com)

Pemanfaatan pemasaran melalui social media dirasakan masih belum maksimal jika dibandingkan dengan pertumbuhan jumlah pengguna internet yang meliputi 56\% penduduk Indonesia. Berdasarkan hasil riset McKinsey, baru sekitar 30\% usaha di Indonesia yang menggunakan instrumen digital dalam mengembangkan usahanya (Supriadi, 2016). Menteri Koperasi dan UKM Puspayoga menegaskan bahwa saat ini UMKM harus benar-benar memanfaatkan internet sebagai bagian dari strategi pemasaran maupun branding produk. Puspayoga pun meyakini bahwa internet dapat meningkatkan penjualan produk UMKM, untuk selanjutnya diikuti dengan peningkatan produksi dan produktivitas UMKM. Tantangan kontinuitas dan kualitas produk yang dapat dihadapi dengan baik akan membuat UMKM sukses dan cepat berkembang (Supriadi, 2016).

Social media marketing menawarkan variasi alat pemasaran yang dapat digunakan secara mudah dan tidak berbiaya, dibandingkan dengan alat pemasaran lainnya (Levinson and Gibson, 2010; Johansson and Corvera, 2012, dalam Rugova and Prenaj, 2016). Dengan biaya yang lebih rendah daripada alat pemasaran yang lain, UMKM cenderung cocok menggunakan metode social media marketing untuk memperkenalkan produknya, membangun hubungan dengan pelanggan dan memperkuat merk nya. Pada kenyatannya, hanya 30\% usaha di Indonesia yang 
menggunakan instrument digital, sehingga dibutuhkan lebih banyak riset untuk mengeksplorasi perspektif dari perusahaan dalam hubungannya dengan social media marketing, terutama dalam memahami penghalang atau penghambat dalam penggunaan social media (Alves, Fernandes and Raposo, 2016).

Tujuan dari riset ini adalah mendeskripsikan konsep pemasaran menggunakan social media atau social media marketing, penggunaan social media sebagai sarana promosi untuk UMKM, dampak dan tantangan dihadapi oleh UMKM dalam penggunaan social media.

\section{Metode Penelitian}

Penelitian ini merupakan penelitian kualitatif, dengan metode studi kepustakaan atau literature review yang merangkai informasi dari berbagai sumber pustaka. Dalam menjawab permasalahan yang ada, maka dilakukan 2 tahap, yaitu (1) merencanakan review yang melibatkan literature-literatur yang berkaitan dengan permasalahan yang ada, (2) melakukan review dan analisis untuk mendeskripsikan fase-fase review dan sistematika dari literature yang berkaitan.

\section{Konsep Pemasaran Dengan Media Sosial atau Social Media Marketing}

Kaplan and Haenlein (2010) menyatakan bahwa social media merupakan aplikasi online yang mempunyai karakteristik seperti aplikasi internet. Pemasaran dengan social media dapat dikategorikan sebagai bagian dari pemasaran dengan internet atau internet marketing (Dahnil et al, 2014).

Social media mampu untuk mengakomodasi keinginan pengguna dalam berinteraksi secara interaktif dan berpartisipasi pada yang mereka minati. Dengan adanya kelebihan cara berkomunikasi yang interaktif dan jangkauan global yang dimiliki oleh social media, maka banyak perusahaan nasional maupun multinasional ataupun UMKM menggunakan social media untuk melakukan komunikasi pemasaran produk/jasa yang dijual kepada para pelanggannya. Social media melampaui pemasaran interaksi antara komputer-manusia dan memperkenalkan interaksi manusia ke manusia yang dilakukan melalui saluran online social media dan menghasilkan konten baru tentang perusahaan (blogging, komentar, jejaring sosial, dan lainnya) (Wicaksono, 2013). 
Menurut Zarrella (2010), social media mempunyai banyak bentuk, namun untuk tujuan pemasaran terdapat 8 macam bentuk social media yang paling banyak digunakan yaitu:

1. Blog; Merupakan website yang isinya berupa tulisan berupa opini dari pemilik blog.

2. Microblog, merupakan bentuk dari blog yang membatasi ukuran setiap posting, misalnya update Twitter hanya dapat berisi 140 karakter. Keterbatasan ini telah melahirkan seperangkat fitur dan perilaku yang sepenuhnya unik untuk media, digunakan oleh banyak perusahaan karena mudah digunakan, hanya memerlukan investasi waktu yang sangat sedikit, dan terbukti dapat dengan cepat menyebarkan informasi, penjualan dan wawasan pelanggan. Perusahaan dapat menggunakannya untuk melakukan penawaran atau peristiwa, dan mempromosikan posting baru dalam blog.

3. Social Networks, adalah sebuah situs tempat individu dapat terhubung dengan teman-teman yang dikenalnya secara offline dan online ataupun dengan temanteman yang hanya dikenal secara online saja. Media ini menjadi topik yang hangat bagi para pemasar, karena social networks hadir dengan sejumlah peluang untuk berinteraksi dengan pelanggan termasuk plug-in aplikasi, groups, dan fanpage.

4. Media-Sharing Sites, sebuah situs berbagi media yang memungkinkan pengguna untuk membuat dan mengunduh konten multimedia. Dengan munculnya kemudahan dalam menggunakan kamera digital dan camcorder serta koneksi Internet berkecepatan tinggi, situs mediasharing telah menjadi sangat popular. Pemasar dapat membuat video dengan keahlian yang sangat kecil dan mengunduhnya ke situs seperti YouTube untuk menjangkau jutaan pengguna. Walaupun website jenis ini menyediakan fitur untuk bergabung menjadi anggotanya, sebagian besar dari pengguna situs tersebut bukanlah terdaftar anggotanya, tetapi hanya untuk sekedar melihat konten.

5. Social News \& Bookmarking, sebuah situs yang memungkin pengguna untuk mengirim dan memilih konten dari seluruh situs tersebut. Hal ini untuk membantu mengetahui link yang paling menarik. Sehingga pemasar dapat menemukan situs yang banyak dikunjungi untuk mendorong penyebaran informasi dalam artikel atau kampanye pemasaran. Beberapa fitur yang membantu pemasaran yang ada di situs ini adalah seperti: profiles, berisi variasi profil pengguna yang menggunakan situs 
tersebut, sehingga mendapatkan informasi tentang konsumen tersebut; summitting, kegiatan yang untuk mengirim suatu konten, pengguna harus terdaftar di sebuah situs social news. Dengan ini pemasar bisa mengetahui konten yang paling banyak diminati oleh pengguna situs tersebut; votting, fitur menarik bagi pemasar untuk membantu melakukan pemasaran di dalam situs tersebut. Melihat konten yang paling popular diantara yang lain sehingga memberikan petunjuk bagi pemasar dalam menentukan konten yang dapat digunakan untuk menarik perhatian para konsumen; Headlines, fitur yang paling penting dan membawa efek paling besar pada seberapa banyak votting yang tertuju. Judul yang menarik akan memberikan kesan bahwa konten tersebut mudah dicerna, menghibur dan berharga. Judul harus eye-catching dan provokatif namun tidak menyesatkan.

6. Review Sites, sebuah situs yang muncul karena berdasarkan survei April 2009 oleh Nielsen Media Research, mengatakan bahwa 70\% kepercayaan konsumen berasal dari pendapat konsumen yang sebelumnya telah membeli atau menggunakan dan diposting secara online, dibandingkan dengan $62 \%$ yang percaya pada iklan di TV, $61 \%$ yang percaya pada iklan di surat kabar dan yang terakhir 59\% yang percaya pada iklan di majalah. Pada situs tersebut, penggunanya sudah berbicara mengenai produk, jasa dan brand online.

7. Forums, merupakan jenis Social media yang merupakan versi modern dari papan buletin masyarakat. Fokus utama dari situs forums adalah mengenai diskusi yang terjadi di dalamnya antara anggota-anggotanya. Dalam hal ini, pemasar harus berhati-hati dalam memilih forum yang akan dimasukinya untuk melakukan kegiatan pemasaran karena umumnya para penggunanya tidak terlalu menyukai iklan.

8. Virtual Worlds, sebuah situs yang di dalamnya berkisar pada permainan dan aktivitas sosial. Situs untuk pengguna bisa menjadi karakter yang diinginkan dan berinteraksi tidak hanya dalam lingkungan atau dunia permainan yang ada. Akan tetapi, kemungkinan untuk pemasar masuk ke situs ini untuk melakukan pemasaran sangat terbatas. Sehingga para pemasar lebih banyak masuk ke virtual world yang berjenis aktivitas sosial. 


\section{Penggunaan Media Sosial Oleh UMKM}

Tujuan utama pemasaran dengan social media adalah amplifikasi dari word-ofmouth marketing, riset pasar, pemasaran secara umum, ide baru dan pengembangan produk, customer service, public relation, komunikasi karyawan dan manajemen reputasi. Pemasaran dengan social media membantu untuk mencapai tujuan pemasaran dengan menggunakan cara non tradisional, melalui penggunaan kretifitas, komunitas dan hubungan yang tidak berbayar. Metode pemasaran dengan social media dapat dianggap sebagau strategi pemasaran guerilla yang sangat kuat. Setiap UMKM dapat mempersenjatai diri dengan alat online marketing yang efektif untuk mempresentasikan produk dan jasanya sama seperti perusahaan besar menawarkan produknya (Rugova and Prenaj, 2016). Pemasaran dengan social media telah melakukan perubahan besar dalam dunia marketing dan memberikan peluang pada UMKM untuk meningkatkan keberadaannya dalam pasar dan memperbaiki image nya (DeMers, 2014; dalam Rugova and Prenaj, 2016).

Sebanyak 57\% UMKM menyatakan social media memberikan manfaat dalam bisnis mereka. Platform social media meningkatkan komunikasi antar merk dan produk, memberikan WOM positif dan negatif dan memberikan exposure yang tinggi dalam waktu yang singkat (Hubspot, 2012; dalam Rugova and Prenaj, 2016).

Dalam Rugova and Prenaj (2016), manfaat atau benefit yang diperoleh UMKM dalam penggunaan social media adalah:

1. Meningkatkan exposure merk

2. Meningkatkan trafik

3. Meningkatkan pelanggan potensial atau prospek penjualan

4. Market insight

5. Meningkatkan efektivitas pemasaran

Wardhana (2015) menyatakan bahwa strategi digital marketing berpengaruh hingga 78\% terhadap keunggulan bersaing UMKM dalam memasarkan produknya. Strategi tersebut terdiri dari: 1. Ketersediaan informasi produk dan panduan produk; 2. Ketersediaan gambar-gambar seperti foto atau ilustrasi produk; 3. Ketersediaan video yang mampu memvisualisasikan produk atau menampilkan presentasi pendukung; 4. Ketersediaan lampiran dokumendokumen yang berisi informasi dalam berbagai format; 
5. Ketersediaan komunikasi online dengan pengusaha; 6 . Ketersediaan alat transaksi dan variasi media pembayaran; 7. Ketersediaan bantuan dan layanan konsumen; 8. Ketersediaan dukungan opini online; 9. Ketersediaan tampilan testimonial; 10. Ketersediaan catatan pengunjung; 11. Ketersediaan penawaran khusus; 12. Ketersediaan sajian informasi terbaru melalui SMS-blog; 13. Kemudahan pencarian produk; 14. Kemampuan menciptakan visibilitas dan kesadaran merek; 15. Kemampuan mengidentifikasi dan menarik pelanggan baru; 16. Kemampuan penguatan citra merek yang diterima oleh konsumen.

Social media menawarkan peluang baik untuk konsumen maupun organisasi. Dengan menggunakan social media, konsumen dapat berinteraksi dengan berbagai merk, menyuarakan opini dan pengalaman mereka terhadap suatu merk dan juga membantu konsumen dalam mencari, mengevaluasi, memilih dan membeli barang dan jasa (Albors, Ramos and Hervas, 2008). Di sisi lain, organisasi memiliki peluang untuk menginvetasikan keberadaan social medianya dan mengembangkan kampanye pada target, berkomunikasi dengan konsumen, menggunakan media untuk mengarahkan direct sales, memperoleh informasi tentang bagaimana konsumen menerima dan mengapresiasi merknya, mendapatkan akuisisi dan retensi pelanggan (Vinerean, 2017)

\section{Dampak Penggunaan Media Sosial Oleh UMKM}

Social media mempunyai dampak positif dan negatif pada bisnis, berikut ini dampak positif yang dikemukakan oleh Lakshmi, Mahboob and Chudhary (2017):

1. Penyebaran informasi yang lebih cepat kepada konsumen

2. Menjangkau konsumen dengan area yang lebih luas

3. Teknologi merupakan asset untuk bisnis

4. Memberikan lebih banyak pilihan dengan mengkreasikan media yang merupakan kombinasi dari audio, visual, teks dan media interaktif

Dampak positif lain dari penggunaan social media menurut Iblasi, Bader and AlQreini (2016), Rugova and Prenaj (2016) adalah kesadaran merk naik, meningkatkan loyalitas merk, lebih banyak peluang untuk meraih pelanggan baru, pelanggan yang sudah ada dan pelanggan lama, trafik percakapan yang meningkat, otoritas merk 
meningkat, inbound traffic meningkat, menurunkan biaya pemasaran, peringkat naik di search engine, memperkaya pengalaman konsumen dengan memberdayakan interaksi yang intens dengan konsumen.

Selain dampak positif, dampak negatif yang ditimbulkan oleh social media terhadap bisnis menurut Lakshmi, Mahboob and Chudhary (2017), adalah:

1. Meningkatkan kekuatan konsumen karena publisitas buruk, ketidakpuasan konsumen juga lebih cepat menyebar

2. Kesulitan untuk mendeteksi pernyataan konsumen yang bersifat negative

3. Ketidaksengajaan melepaskan informasi yang penting atau rahasia

4. Kesulitan untuk memonitor aktivitas social media dari karyawan dan mencegah untuk membuat pernyataan tanpa autorisasi.

Penggunaan social media pada UMKM juga membantu meningkatkan volume penjualan pada UMKM. Peningkatan paling banyak dirasakan UMKM sebesar 10-15\% (Purwidiantoro, Kristanto dan Hadi, 2016). Social media marketing lebih efektif untuk membangun kesadaran merk dan mengembangkan reputasi merk serta meningkatkan penjualan (Pentina, Koh and Le, 2012). Survey yang dilakukan oleh Socialmediatoday mengungkapkan bahwa $71 \%$ pengguna social media cenderung untuk membeli produk dari merk yang terkoneksi di website social media (Iblasi, Bader and Al-Qreini, 2016). Konsumen membuat keputusan pembelian berdasarkan informasi yang mereka terima melalui media massa, akan tetapi, dalam masa sekarang, jaringan social online mempunyai kekuatan yang mempengaruhi keputusan pembelian konsumen (Solomon, et al, 2014; Alhabash et al, 2015; Hoffman et al, 2014; Hong, 2012; dalam Alves, Fernandes and Raposo, 2016). Sebanyak 54\% keputusan konsumen dipengaruhi oleh komunikasi dari social media (Lovett and Staelin, 2016). Perusahaan yang lebih aktif di social media dapat meningkatkan value nya lebih baik (Wang and Kim, 2017).

\section{Tantangan Dalam Pemasaran dengan Sosial Media Oleh UMKM}

UMKM di negera berkembang mulai menggunakan social media dalam pemasaran produknya, akan tetapi keberadaan masih jauh tingkatannya dibandingkan dengan UMKM di negara maju (Rugova and Prenaj, 2016; Oztamur and Karakadilar, 2014). Hanya sedikit pemilik UMKM yang menggunakan social media sebagai media 
promosi dan tidak membedakan akun pribadi dengan akun online shop, dan penggunaan social media secara tidak berkala. Pemilik UMKM yang lain tidak menggunakan social media karena kurangnya kemampuan dalam menggunakan teknologi (Purwana, Rahmi, Aditya, 2017).

Hal yang sama terjadi juga di Malaysia, UMKM menghadapi kekurangmampuan dalam mengikuti perkembangan teknologi dalam memasarkan produknya (Hashim, 2007; dalam Dahnil et al., 2014). UMKM juga mempunyai keunikan dengan keterbatasan dalam sumber daya, modal, SDM dan teknologi (Davis and Vladica, 2006; dalam Dahnil et al., 2014:120). Dibandingkan dengan perusahaan yang lebih besar, kebanyakan UMKM terkendala dalam implementasi IT dalam bisnisnya karena mahal, resiko, prosedur yang kompleks, membutuhkan teknisi dan customer service (Chong et al, 2012; Pires and Aisbett, 2001). Dengan menggunakan Actor Network Theory, Sarosa (2012) juga menyatakan bahwa dalam adopsi jaringan social media (social media network) oleh UMKM di Indonesia, penggunaan jaringan akan berhasil jika actor kunci dapat mengarahkan actor lain dan lingkungannya.

Keberhasilan adopsi pemasaran dengan menggunakan social media sangat tergantung pada kontribusi factor internal seperti pemilik dan karyawan, selain factor managerial dan organisasi. Determinan ekternal seperti lingkungan bisnis dan ekonomi global juga berpengaruh pada keberhasilan adopsi pemasaran dengan social media (Dahnil et al, 2014).

Tantangan lain dalam pemasaran dengan social media adalah resiko yang terjadi ketika privasi, keamanan, menjadi tidak hal yang terbuka dan dapat diakses oleh banyak pihak karena aktivitas social media juga bersinggungan dengan hukum dalam teknologi informasi (Rugova and Prenaj, 2016).

\section{Pembahasan}

Sebagai negara dengan jumlah penduduk yang mencapai 260 juta, 56\% diantaranya adalah pengguna social media. Dengan demikian, dapat dikatakan bahwa Indonesia mempunyai peluang yang besar dalam implementasi social media marketing. Social media marketing menyediakan platform yang dapat digunakan untuk membangun komunikasi dan relasi yang intens dengan pelanggan. 
Sebanyak 3,79 juta dari 59,2 juta UMKM di Indonesia telah go online (CNN Indonesia). Angka ini masih lebih kecil dibandingkan UMKM di negara-negara maju yang telah menggunakan social media marketing (Rugova and Prenaj, 2016; Oztamur and Karakadilar, 2014).

Meskipun social media marketing memiliki manfaat dan dampak yang positif maupun negative, akan tetapi tantangan dalam implementasinya juga tidak sedikit. Factor internal seperti ketidakmampuan dalam bidang teknologi, ketersediaan tenaga ahli atau karyawan untuk maintance platform, ketidakmampuan dalam investasi modal di bidang teknologi, menjadi factor yang menyebabkan UMKM belum mengimplementasikan social media marketing. Didukung dengan kecepatan perkembangan teknologi, persaingan bisnis yang menggunakan media online, kemungkinan kebocoran privasi atau keamanan akun, turut menyumbang keengganan UMKM dalam implementasi social media marketing.

Untuk menghadapi dan mengantisipasi tantangan ini dan tetap memperoleh manfaat dari social media marketing, maka dalam penggunaan social media, UMKM hendaknya focus pada pengembangan strategi pemasaran yang menekankan pada memperkuat hubungan dengan pelanggan. Berbagai tipe komunikasi diciptakan, dikembangkan dan dibagikan dalam social media serta ditransformasikan dalam bentuk iklan. Yang kemudian iklan ini dapat dihubungkan dengan berbagai diskon, ataupun sales promotion yang lain. Sebelum mengintegrasikan social media dengan alat komunikasi pemasaran lainnya, maka harus dikenali alat dan channels yang tepat untuk masuk ke dalam grup target, menciptakan pesan yang atraktif dan dapat diterima oleh semua konsumen (Jucaityte and Mascinskiene, 2014). Untuk meningkatkan keberhasilan dalam penggunaan social media, Vinerean (2017) menyatakan bahwa perlu untuk:

- Menciptakan pengalaman personal untuk pelanggan

- Menciptakan strategi content yang efisien dan konsisten di tiap platform social media yang digunakan (misalkan video, image, gifs, blog posts, podcast, dll)

- Menciptakan komunitas yang loyal, yang dibentuk dari audiens untuk mengembangkan publistas merk dan influencer

- Merumuskan ulang content atau isi pesan dan membagikan melalui social media 
- Melakukan riset, memonitor dan mempelajari pelanggan berdasarkan percakapan yang terjadi di social media, sehingga dapat memberikan umpan balik dan yang dibutuhkan.

\section{Kesimpulan}

Memasarkan produk melalui social media lebih murah daripada memasarkan produk melalui outlet retail. Social media marketing mampu menawarkan produk secara personal, hanya dengan membuat profil history dari pembelian dan preferensi konsumen. Banyak pengusaha menggunakan social media untuk membangun komunitas bisnisnya. Komunitas ini digunakan untuk menyebarluaskan percakapan, memberikan kesadaran, meningkatnya jumlah pengikut (follower), memberikan reward pada fans dan menjalin hubungan dengan pelanggan.

Merencanakan untuk menggunakan social media sebagai alat pemasaran yang kompetitif, memerlukan isi pesan yang dapat menarik perhatian pelanggan. Selain itu, juga dibutuhkan ketulusan, perhatian dan respon dengan cepat dalam berkomunikasi dengan pelanggan target.

Tantangan dalam penggunaan social media marketing oleh UMKM yang meliputi ketidakmampuan mengikuti teknologi, modal, factor manusia, resiko kebocoran privasi, merupakan hal yang harus dihadapi dan diantisipasi agar mencapai keberhasilan dalam social media marketing.

\section{Daftar Pustaka}

Albors, J. Ramos, J.C and J.L. Hervas. (2008). New Learning Network Paradigm: Communities of Objectives, Crowdsourcing, Wikis and Open Source. International Journal of Information Management, 28: 194-202.

Alves, Helena. Fernandes, Cristina and Mario Raposo. (2016). Social Media Marketing: A Literature Review and Implication. Psycology and Marketing Vol. 33 (12) December 2016: 1029-1038.

Chong, A. Y.-L., Chan, F. T. S., \& Ooi, K.-B. (2012). Predicting consumer decisions to adopt mobile commerce: Cross country empirical examination between China and Malaysia. Decision Support Systems, 53(1), 34-43.

Dahnil, Mohd Irwan. Marzuki, Kamarul Mizal. Langgat, Juliana. And Noor Fzlinda Fabeil. (2014). Factors Influencing SMEs Adoption of Sosial Media Marketing. Procedia-Social and Behavioral Sciences 148 (2014) 119-126. 
Eagleman, A. N. (2013). Acceptance, Motivations, And Usage Of Social Media As A Marketing Communications Tool Amongst Employees Of Sport National Governing Bodies. Sport Management Review.

Iblasi, Walid Nabil. Bader, Dojanah M.K. and Sulaiman Ahmad Al-Qreini. (2016). The Impact of Social media as a Marketing Tool on Purchasing Decision (Case Study on SAMSUNG for Electrical Home Appliances. International Journal of Managerial Studies and Research (IJMSR), Vo. 4 (1) January 2016: 14-28.

Jucaityte, Indre and Jurate Mascinskiene. (2014). Peculiarities of Social Media Integration Into Marketing Communication. Procedia-Social Behavioral Sciences 156 (2014): 490-495.

Kaplan, A. M., \& Haenlein, M. (2010). Users Of The World, Unite! The Challenges And Opportunities Of Social Media. Business Horizons, 53(1), 59-68.

Lakshmi.V. Mahboob, Afraa and Ankita Choudhary. (2017). A Study On Impact Of Social Media On Small And Medium Enterprises. International Journal of Scientific Development and Research (IJSDR) Volume 2, Issue 11: 64-71.

Lovett, M.J. and R. Staelin. (2016). The Role of Paid, Earned and Owned Media in Building Entertainment Brands: Reminding, Informing and Enhancing Enjoyment. Marketing Science, 35(1): 142-157.

Öztamura, Dilhan and İbrahim Sarper Karakadilarb. (2014). Exploring The Role Of Social Media For Smes: As A New Marketing Strategy Tool For The Firm Performance Perspective. Procedia - Social and Behavioral Sciences 150 ( 2014 ) $511-520$.

Pentina, I. Koh, A.C. and T.T Le. (2012) Adoption of Social Network Marketing by SMEs: Exploring The Role of Social Influences and Experience in Technology Acceptance. International Journal Internet Marketing and Advertising, 7(1): 65-82.

Purwana, Dedi. Rahmi. dan Shandy Aditya. (2017). Pemanfaatan Digital Marketing Bagi Usaha Mikro, Kecil, Dan Menengah (UMKM) Di Kelurahan Malaka Sari, Duren Sawit. Jurnal Pemberdayaan Masyarakat Madani (JPMM) Vol. 1 No. 1 Juli 2017: 1-17.

Purwidiantoro, Moch Hari. Kristanto S.W., Dany Fajar dan Widiyanto Hadi. (2016). Pengaruh Penggunaan Media Sosial Terhadap Pengembangan Usaha Kecil Menengah (UKM). Jurnal EKA CIDA Vol. 1 No. 1 Maret 2016: 30-39.

Rugova, Blerta and Burim Prenaj. (2016). Social Media as Marketing Tool fo SMEs: Opportunities and Challenges. Academic Journal of Business, Administration, Law and Social Sciences Vol 2 No. 3 November 2016: 85-97.

Sarosa, S. (2012). Adoption of Social Media Networks by Indonesian SME: A Case Study. Procedia Economics and Finance, 4(Icsmed), 244-254.

Solomon, M. Bamossy, G. Askegaard, S and M. Hogg. (2010). Consumer Behavior: Buying, A European Perspective. Financial Times Press. 
Supriadi, C. (2016). Retrieved February 18, 2017, from http://www.marketing.co.id: http://www.marketing.co.id/dukung -wirausaha-wanita-lewat-aplikasi-dbsbusinessclass/

Vinerean, Simona. (2017). Importance of Strategic Social Media Marketing. Expert Journal of Marketing, Vol. 5 (1): 28-35.

Wang, Z. and Kim, H.G., (2017). Can Social Media Marketing Improve Customer Relationship Capabilities and Firm Performance? Dynamic Capability Perspective. Journal of Interactive Marketing, 39, pp.15-26.

Wardhana, A. (2015). Strategi Digital Marketing dan Implikasinya pada Keunggulan Bersaing UKM di Indonesia.

Wicaksono. Kuspuji Catur Bagus. (2013). Mengukur Efektivitas Social Media Bagi Perusahaan. Binus Business Review Vol. 4 No. 1 Mei 2013: 551-564.

www.wearesocial.com

Zarella, Dan. (2010). The Social Media Marketing Book 